\title{
Textual Analysis of Condominium Flyers in Cebu
}

\author{
Rowanne Marie R. Maxilom, Christy T. Constantino \\ Department of Communications, Linguistics \& Literature, University of San Carlos, Cebu City, Philippines
}

Email address:

rmmaxilom@gmail.com (R. M. R. Maxilom), christyconstantino@gmail.com (C. T. Constantino)

\section{To cite this article:}

Rowanne Marie R. Maxilom, Christy T. Constantino. Textual Analysis of Condominium Flyers in Cebu. International Journal of Education, Culture and Society. Vol. 2, No. 6, 2017, pp. 195-202. doi: 10.11648/j.ijecs.20170206.16

Received: April 18, 2017; Accepted: July 6, 2017; Published: December 19, 2017

\begin{abstract}
This study aimed to describe and analyze the contents evident in the selected flyers of condominium projects. This study used the descriptive type of research method as it focused on the mandatory contents present in the selected thirty flyers of condominium projects in Cebu. Results revealed that the exact location of the project including the street, name of the owner or developer and license to sell or amended license to sell number are the mandatory contents evident in the flyers. Moreover, the newly-discovered contents include the landmarks, location \& distance in kilometers/meters as well as the website of the developers. This study provides implications to the successful implementation of the guidelines set by the Housing and Land Use Regulatory Board.
\end{abstract}

Keywords: Advertisement, Condominium, Cebu, Flyers, HLURB, Projects, Textual Analysis

\section{Introduction}

With the influx of real estate projects where condominiums are increasing in Cebu, there is a need to analyze the contents of the brochures \& flyers whether the developers with their graphic artists follow the implementing rules and regulations concerning advertisements set by the Housing and Land Use Regulatory Board (HLURB) Board Resolution 921 Series of 2014 and the corresponding guidelines indicated in Memorandum Circular 1 Series of 2015. In this manner, the HLURB guidelines for advertisements could be revisited through the output of this study.

In the Philippines, the print advertisements inclusive of the flyers are regulated by the Housing and Land Use Regulatory Board (HLURB). "The Housing and Land Use Regulatory Board (HLURB) plays the role as the lead agency in the provision of technical assistance to local government units in the preparation of comprehensive land use plans; regulation of housing, land development and homeowners association; and adjudications of disputes related thereto...." ("Quality Policy," 2016). This government agency is committed to deliver its services with competence and integrity to satisfy its stakeholders. Specifically, HLURB has the following powers as stated in Executive Order No. 71 Section 1 (a)-(e): (a) approval of preliminary as well as final subdivision schemes and development plans of all subdivisions, residential, commercial, industrial and for other purposes of the public and private sectors, in accordance with the provisions of PD No. 957 as amended and its implementing standards, rules and regulations concerning approval of subdivision plans; (b) approval of preliminary and final subdivision schemes and development plans for all economic and socialized housing projects as well as individual or group building and occupancy permits covered by BP 220 and its implementing standards, rules and regulations; (c) evolution and resolution of opposition against the issuance of development permits for any of the said projects, in accordance with the said laws and the Rules of Procedure promulgated by HLURB incident hereto; (d) monitoring the nature and progress of land development of projects it has approved, as well as housing construction in the case of house and lot packages, to ensure their faithfulness to the approved plans and specifications thereof, and imposition of appropriate measures to enforce compliance therewith; and (e) assessment and collection of fees incident to the foregoing.

\subsection{Contents of the Flyers}

Furthermore, HLURB provides guidelines for the use and dissemination of print advertising as articulated in the Memorandum Circular 1 Series of 2015. The "2014 
Guidelines to advertisements" (2016) emphasize the mandatory contents of the print ads which include flyers and any materials for promotional purposes of the projects related to real estate. As stated in Memorandum Circular 1 Series of 2015 Section 12, these are the mandatory contents: (a) names of the owners and/or developers of the project; (b) exact location of the project including street name, barangay, and city or municipality; (c) the license to sell or amended license to sell number; (d) the advertisement approval number; (e) the approved project completion date as indicted in the license to sell; (f) the maximum selling price in case of economic and socialized housing projects. In this manner, these would be the mandatory contents that would be the framework in looking into the flyers that would be analyzed. Moreover, Section 9 of "Memorandum Circular 1 Series of 2015" (2016) mentioned that "the location and distance of the project must be stated in a manner that will not tend to mislead the public or prospective buyers of its proximity and value. Any statement of the project's location and distance in relation to a known place or landmark shall be expressed in terms of kilometers, and any vicinity map illustrating such proximity to known places or landmarks must similarly indicate such distance or distances in terms of kilometers" ( $p$. 6).

However, there are still print advertisements, specifically flyers that contain contents that do not follow the mandated guidelines set by the HLURB.

Furthermore, Maruani \& Cohen (2013) pointed out in their article titled "Marketing landscapes: The use of landscape values in advertisements of development projects" that the components of typical advertisements consist of (i) a graphic illustration, (ii) heading, which can be a slogan that accompanies the given campaign all along or a catchy phrase that was designed for the specific advertisement, (iii) logo of the project name (iv) a short text describing the project's advantages, (v) the developer's name or logo, and (vi) the contact details (such as telephone number, address or website) of the sales office. On the contrary, not all of these typical components are included in the mandatory contents as mentioned by the HLURB guidelines.

Ladd (2010) also pointed out that aside from providing information to influence a purchasing decision, the designers of brochures should collect the useful information that will be included in the brochure. These include description of the enterprise, descriptions of the products and services, contact information (i.e. mailing address, phone number, fax number, e-mail address, website), hours of operation, special events or seasonal calendar, directions/maps, visual elements (i.e. logo, photographs, illustrations or clip art images), testimonials and recent publicity or news articles. Consequently, the contents of the flyers could still contain the typical contents of print advertisements.

\subsection{Review of Related Literature}

As reviewed, there have been few studies that dealt with the contents of the print advertisements. These empirical studies include Dayag (2008), Nugroho (2009) on the magazine with the print ad of moisturizing cream, Maruani \& Cohen (2013) on the real estate advertisements, Javillonar (2016) on billboards \& Barabas (2017) on brochures of university prospectuses. First, Dayag (2008) aimed at investigating the generic structures and linguistic properties of print ads in Philippine magazines. The data were gathered from the Corpus of Asian Magazine Advertising: The Philippine Database consisting of seventy-four ads intended for consumer nondurables such as medicines, vitamins and food supplements, and cosmetic, beauty, personal hygiene products. The findings showed that the ads illustrated preference for certain generic structures and linguistic features letting them 'reason' (rather than 'tickle') ads that could be described as direct. On the contrary, the present study focused on flyers not from the magazines in advertising real estate products. Second, Nugroho (2009) analyzed the generic structure of print advertisement of Elizabeth Arden's moisturizing cream, "Intervene" based on the systemicfunctional linguistics by Halliday (1985, 1994 in Nugroho, 2009) and Halliday and Mathiessen (2004 in Nugroho, 2009). The visual images were also analyzed using O'Toole (1994 in Nugroho, 2009). However, this study only focused on the moisturizing creams including the visual images which were not the focus of the present study.

Third, Maruani \& Cohen (2013) proved the claim that argued that "the widespread use of signs and symbols which represent landscape values in advertising maybe regarded as expressing prevailing preferences of the public...." (Maruani \& Cohen (2013, p 92) through analyzing the 85-full page promotional advertisements of development projects in Israel. This study is very related to the present study because of the similar advertisements used in the data, that is, real estate print ads although the present study used the term flyers. This study also provided a discussion of the contents of the flyers which are the main focal points of the present study. Fourth, Javillonar (2016) determined and analyzed the discourse features which affected the values, beliefs and power of the consumers. One hundred thirty five local and international billboards were analyzed from various locations in Metro Manila. To validate, survey questionnaires were distributed to one hundred twenty respondents aged $18-70$ years old. Results showed that the linguistic features of nouns and adjectives predominated in the slogans of billboards to create positive appeal to the audience; colors red, white, and blue, the center position, the smiling gesture of the endorser, and larger fonts were the common visual features in billboards. New symbols \# and @ signs were evident. This study concluded that Filipino consumers argued that their values and beliefs were recalled and enhanced through billboard messages. This study is relevant to the present study because of genre used in analysis which is another type of print advertising. The symbols \# and @ are also evident in the flyers of real estate.

Finally, Barabas (2017) conducted a genre analysis of brochures of prospectuses in Philippine universities. Specifically, he analyzed the rhetorical moves, functional constituents as realized by verbs, word combinations and 
linguistic elements in the twelve brochures of nine universities. Findings of his study revealed eight rhetorical moves, material process, free combinations, use of modal and permissive modal auxiliaries were employed in the brochures. This study is very useful in the present study since it also mentioned that location is evident in all brochures. However, the present study deals with flyers of condominiums instead of university brochures of prospectuses. In sum, these reviewed studies provide similar data and helpful insights.

\subsection{Statement of the Problem}

This study aimed to describe and analyze the contents evident in the selected flyers of condominium projects. Specifically, this study attempted to answer the following questions:

(a) What contents are found in the flyers of condominium projects based on the mandatory contents in print advertising implemented by HLURB Sec. 12 Memorandum Circular 1 Series of 2015 ?

(1) The names of the owners and/or developer of the project

(2) The exact location of the project including street name, barangay, and city or municipality

(3) The license to sell or amended license to sell number

(4) The advertisement approval number

(5) The approved project completion date as indicated in the license to sell

(6) The maximum selling price in case of economic and socialized housing projects

(7) HLURB Registration numbers of offices, of the dealers or any of the projects authorized brokers or salespersons

(b) What are the newly-discovered contents of the flyers?

\section{Methodology}

\subsection{Research Design}

The present study made use of the descriptive type of research method as it focused on the mandatory contents present in the selected thirty flyers of condominium projects in Cebu City. Specifically, the use of textual analysis as the foremost technique in this study may be best explained by the fact that the present researchers described and interpreted the characteristics found on the visual messages represented by the flyers. It could be adhered to the fact that the purpose of the present study was not only to describe but to fully reflect on the content, structure, as well as functions of the texts.

\subsection{Research Environment}

The flyers were gathered from various locations such as developers, Global One Realty during the product knowledge seminars, and malls where there were exhibits of condominiums.

\subsection{Research Data}

The thirty condominium flyers that served as corpus for this study were taken from developers, Global One Realty during the product knowledge seminars, and malls where there were exhibits of condominiums. These were collected from January 2015- May 2016 using the purposive sampling technique with the following criteria: flyers with only front and back pages, flyers of condominiums only in Cebu City and neighboring cities and suburban areas in Cebu province, distributed flyers from January 2015- May 2016.

\subsection{Research Instruments}

The interviews with Real Estate brokers were used as the instruments in the study. One of the present researchers conducted interviews last February $22 \& 23,2017$ to further validate the results on the contents of the flyers.

\subsection{Research Procedure}

\subsubsection{Gathering of Data}

Given that Textual Analysis was utilized in the present study, considerations were made in the process of choosing the thirty condominium flyers. The purposive sampling method was used in picking the thirty condominium flyers which contained the mandatory contents as specified in print advertising implemented by HLURB Sec. 12 Memorandum Circular 1 Series of 2015. Each condominium flyer was analyzed by looking at the emergence of specific contents such as: (a) names of the owners and/or developers of the project; (b) exact location of the project including street name, barangay, and city or municipality; (c) the license to sell or amended license to sell number; (d) the advertisement approval number; (e) the approved project completion date as indicted in the license to sell; and ( $f$ ) the maximum selling price in case of economic and socialized housing projects.

\subsubsection{Treatment of Data}

The authors specifically used content analysis in verifying the texts present in the flyers. Each thirty flyer was examined and the number of times that any of the seven mandatory contents as mentioned above were counted. After which, sample lines were taken from the condominium flyer and the average of the frequency of the contents were coded by the two researchers based on the conventions in print advertisements. To sum up, those contents not specified in the print advertisement regulations were summarized to answer sub - problem no. 2 .

\section{Results and Discussion}

This section focuses on the presentation, analysis and interpretation of the contents of flyers. First, the mandatory contents of the flyers based on the regulations in print advertisements will be discussed. The second part deals with the newly-discovered contents of the flyers which can be basis for the guidelines. Lastly, the proposed additional guidelines will be formulated to help the Housing Land Use Regulatory Board in revising the guidelines. 


\subsection{Mandatory Contents of Flyers}

Table 1 presents the mandatory contents of the flyers such as the exact location of the project including the street (28.5), name of the owner/developer (27.5) as well as the license to sell or amended license to sell number (17).

Table 1. Mandatory Contents of Flyers $N=30$.

\begin{tabular}{|c|c|c|}
\hline Contents & $*_{f}$ & Examples \\
\hline Exact location of the project including the street & 28.5 & $\begin{array}{l}\text { F1L19: Amaia Steps Mandaue is located at Plaridel St., UN Ave. Brgy. } \\
\text { Alang-Alang, Mandaue City, Cebu } \\
\text { F4L14 - 15: MJ Cuenco Avenue, Corner Holy Name St. Cebu City } \\
6000 \text { Philippines }\end{array}$ \\
\hline Name of the owner/developer & 27.5 & $\begin{array}{l}\text { F1L25: Amaia Southern Properties, Inc. } \\
\text { F4L9: Grandland } \\
\text { F1L20: LS\#: } 29572\end{array}$ \\
\hline License to sell or amended license to sell number & 17 & $\begin{array}{l}\text { F2L29: HLURB License to Sell \# 25440, } \\
\text { 26286 \& } 26294\end{array}$ \\
\hline the advertisement approval number & 12.5 & $\begin{array}{l}\text { F1L23: Advertising Approval \#: CVR-15-056 } \\
\text { F7L29: Advertising Approval No. CVR- } 015-013\end{array}$ \\
\hline $\begin{array}{l}\text { the approved project completion date as indicted in } \\
\text { the license to sell }\end{array}$ & 7 & $\begin{array}{l}\text { F1L22: Completion Date: May2018 } \\
\text { F7L30: Completion Date: May 9, } 2016\end{array}$ \\
\hline $\begin{array}{l}\text { the maximum selling price in case of economic and } \\
\text { socialized housing projects. }\end{array}$ & 4 & $\begin{array}{l}\text { F5L15: Php 3.6 M }-4 \mathrm{M} \\
\text { F5L } 21 \& 26: \text { Php } 2.5 \mathrm{M}-2.9 \mathrm{M} \& \text { Price Range for } 1^{\text {st }} \text { batch: Php } 1.4 \mathrm{M}- \\
3.3 \mathrm{M} \\
\text { (other prices indicated in one flyer) }\end{array}$ \\
\hline
\end{tabular}

*f is the average of the frequency of the contents coded by the two authors.

To explain the predominance of location in the flyers, the real estate, specifically, the condominiums are considered immovable properties. In this manner, it is important for the prospective buyers to be knowledgeable about the specific location of the project. This result supports the study of Barabas (2017) whose study was on the genre analysis of brochures of university prospectuses wherein the location is one of the important contents found in the said print advertising material. As a matter of fact, Barabas (2017) pointed out that identifying the location is significant to commuters.

Figures 1 below presents the front cover of Flyer 4 where the location is directly observable.

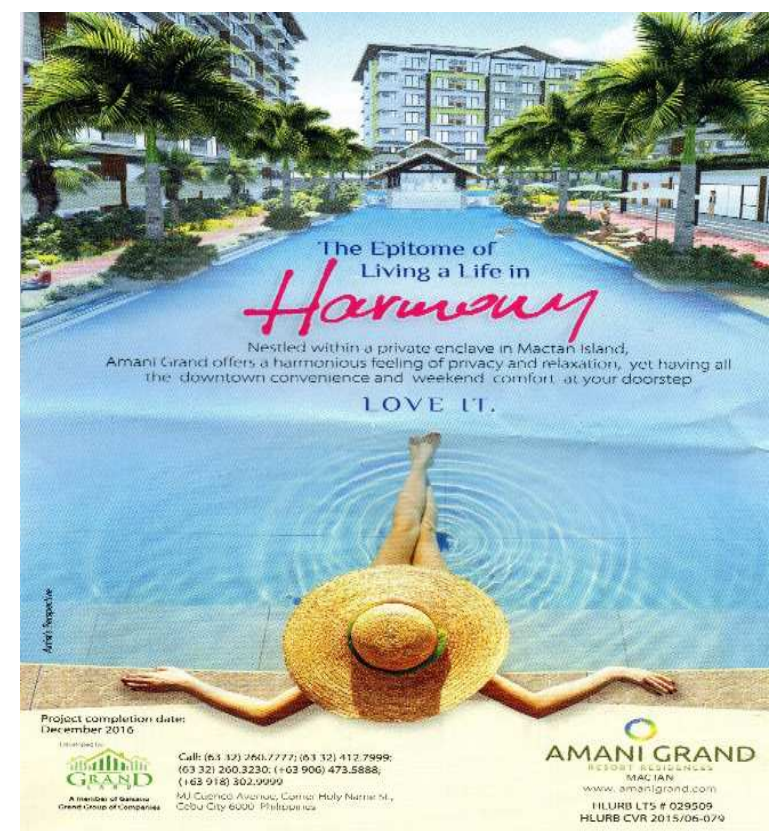

Figure 1. Amani front.
Flyer 4 displays how the exact location could be readily viewed on the front cover of the advertisement. It could be seen that together with the location information and right after the enticing image, accompanying details such as the project completion date, contact information, amended license to sell number and the call and visit information (www.amanigrand.com) are noticeable. Majority of the 30 flyers $(28.5 \%)$ showcase how the ad designers have chosen to project the location information right in front given the fact that most individuals these days opt for what is nearby and convenient. Therefore, allowing them to feel easiness as they make their choices for a possible place to live in.

This result further implies that the majority of the advertisers conform to the Memorandum Circular Series 1 of 2015 of HLURB which is mainly based on HLURB Board Resolution 921 which governs the advertisements of condominiums and subdivision projects. Moreover, the buyer's capacity to buy is associated with the location (Interview, Galeon*, 2017). According to the interviewed real estate broker, buyers who can afford very expensive condominiums tend to choose locations that are very accessible.

There are truly definite indicators of quality that each home buyer and/or investor looks out for. With the advent of a number of developers partaking in Cebu's booming property industry, potential buyers could oftentimes easily get overwhelmed with information. This thought leads us to the second topmost mandatory content gathered in the present research. The sustainability and durability of the condominiums are usually attributed to the developers' credibility and stability. Not only do interested buyers focus on the proximity factor of the property's location, but they also deliberate on the truthfulness of the developer.

Figures 3 and 4 (Flyer 1) below show the presence of the developer's name right on the front cover of the flyers. 


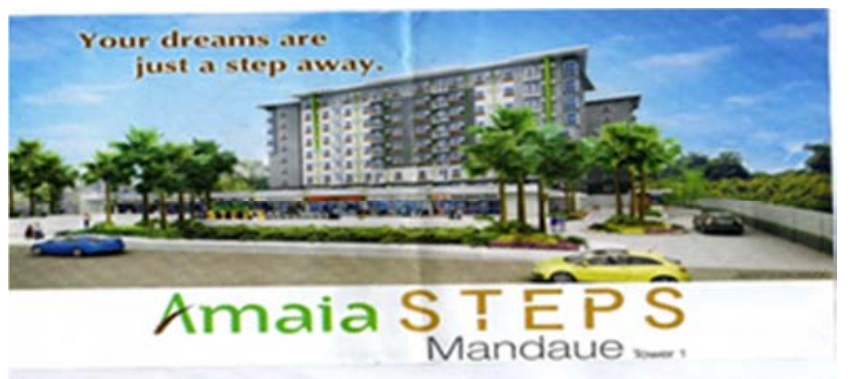

Figure 2. Amaia front.

Majority of the 30 flyers $(27.5 \%)$ illustrate the presence of the developer's name on the marketing material. It could be observed in Figure 2 how the developer's name is shown in a more pleasing font style as well as a bigger font size as compared to the other mandatory contents. The results reveal that names of the owner or developer included: Filinvest, Apple One Properties, Inc., Grandland, Taft Properties, Sta. Lucia Land Inc., Cebu Landmasters, Primary Homes Incorporated and LandTraders World Properties Corp.

If the developer has been in the industry for years, then it has already established its credibility and prestige. In particular, an article posted by PropertyAsia.Ph dated February 17, 2017, revealed that Primary Homes Incorporated is part of Cebu's Top Property Developers hence typifying integrity among prospective buyers since it is one of the leading real estate developers in the metropolis. This result then confirms the claim of Muruani \& Cohen (2013) in relation to the presence of developer's name in the advertising material. In fact, they presented the components of a typical advertisement which includes “...the project's advantages, the developer's name or logo..." (Muruani \& Cohen (2013, p. 94). Prospective buyers would make it sure that the developer is trustworthy (Interview, Maxilom*, 2017) and prestigious such as Aboitizland (Interview, Galeon*, 2017). Aside from the location and developer's name, the license to sell is also evident in the flyers understudy. Obviously, this should be found in the flyers and any print advertising because it is mandated by the Housing and Land Use Regulatory Board (HLURB, MC Series 1 2015).

Figures 3 (Flyer) below displays the license to sell information of the flyer.

In detail, the license to sell feature is situated on the back cover of the flyer. It may not be the most salient feature presented in the printed ads, but this is considered as the third topmost mandatory content found among the 30 flyers. In addition, it could be observed that most of the license to sell information are signified with the tiniest font size as compared to all other flyer information. On the contrary, only 17 out of 30 flyers contain the said license to sell. It implies that there are still many developers that deviate from the Memorandum Circular mandated by HLURB probably because of lack of information dissemination, negligence on the part of the developer/owner, lack of monitoring, inability to follow the memorandum seriously, etc. This absence of license to sell probably implies that some flyers have been distributed for announcement purposes only. In sum, the exact location of the project, name of the developer and license to sell are the predominant components of the analyzed flyers.

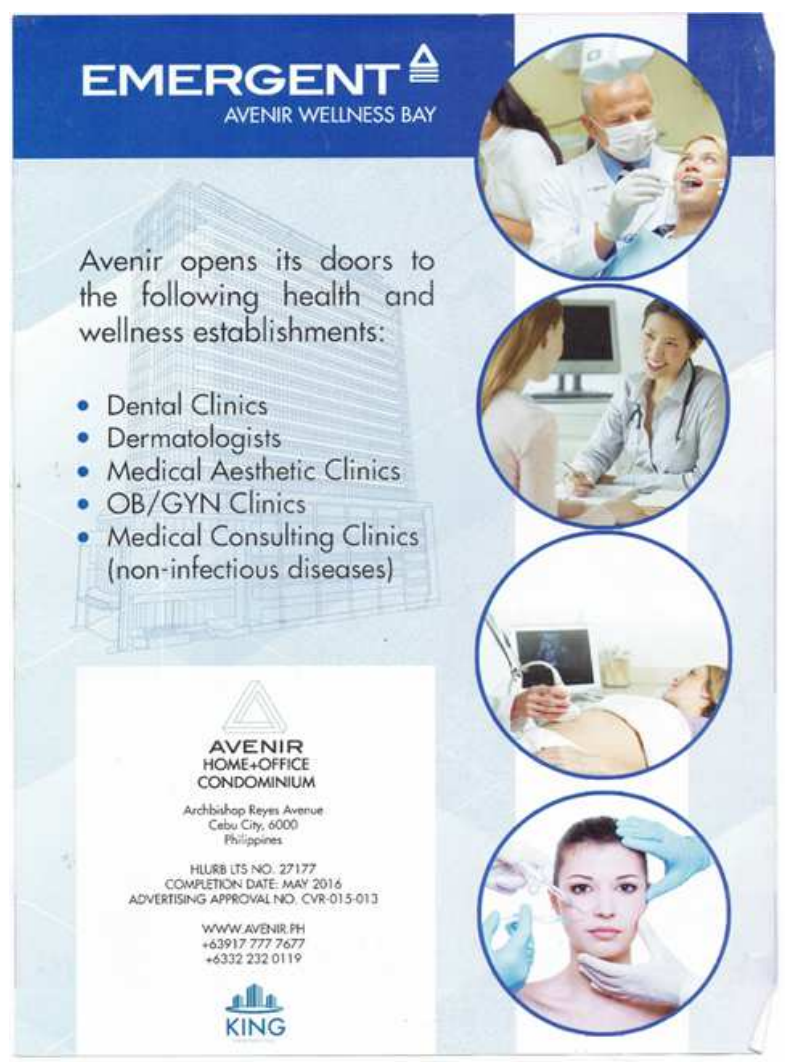

Figure 3. Avenir back.

\subsection{Newly-Discovered Contents of the Flyers}

Table 2 shows very important results on the newlydiscovered contents of the flyers. These include the landmarks (17.5), location \& distance in kilometers (6.5), website of the developer (5.5).

Table 2. Newly-Discovered Contents of the Flyers $N=30$.

\begin{tabular}{lll}
\hline Contents & *f & Examples \\
\hline \multirow{2}{*}{ Landmarks } & \multirow{2}{*}{17.5} & F7L7 - 8: Avenir is located in the heart of Cebu the fastest growing economy in the country \\
& & F4L2: Nestled within private enclave in Mactan Island \\
& & F7L9-11: 700 meters from I.T. Park \\
& & 500 meters from Waterfront Hotel - Lahug \\
& & 900 meters from Cebu Business Park \\
location \& distance in kilometers/meters & \multirow{2}{*}{6.5} & F27L27-30: Commercial Centers: \\
& & SM City Cebu: 30M \\
& Parkmall: 2.8 KM \\
& S \& R: 1.8 KM \\
&
\end{tabular}




\begin{tabular}{|c|c|c|}
\hline Contents & $*_{f}$ & Examples \\
\hline website of the developer & 5.5 & $\begin{array}{l}\text { F4L18: www.amanigrand.com } \\
\text { F5L41: www.appleonecebu.com }\end{array}$ \\
\hline disclaimer & 3.5 & $\begin{array}{l}\text { F19L23: For announcement purposes only. } \\
\text { F25L20: Note: Images shown are architects' } \\
\text { perspectives only. }\end{array}$ \\
\hline space for the seller & 2.5 & \\
\hline contact numbers & 2 & $\begin{array}{l}\text { F3L35-36: For price inquiries, questions and to } \\
\text { schedule tour of the model units, you may } \\
\text { contact: }(+63-32) 262-5438 /(+63) \\
\text { 0922874662 } \\
\text { F7L25-27: }+63322320119 \\
+639177777677 \\
+63324158330\end{array}$ \\
\hline symbol of social media & 1.5 & \\
\hline
\end{tabular}

For the newly-discovered contents of flyers not included in the listed mandatory contents, it is not surprising that landmarks are evident in the flyers. Since condominiums are usually located in cities or urban areas, indicating the landmarks and nearby commercial establishments can assist in locating the specific locations. In addition, the direction of the condominium project is easier to locate because of the available landmarks (Interview, Maxilom, 2017). In fact, the landmarks should also be included in the list of mandatory contents because it is helpful to both sellers and buyers in locating the site. (Interview, Galeon, 2017).

Landmarks would also entice the prospective buyers since these landmarks, especially malls and other commercial areas can contribute to the accessibility and convenience of the condominium owners. The results of the present study reveal that majority of the landmarks are positioned at the back cover of the flyers. It is either labelled as vicinity or site map and these markers could be viewed typically on the right portion of the back cover of the flyers placed after images on the condominiums' amenities. According to Harris (2011 in Webber \& Webb (2017), "the desire for home ownership and its perceived investment benefits remains a strong source of demand in many of these locations. As a result, condominium ownership ... has been utilized to provide ownership options that also stimulate residential investment in urban areas (p. 48).

Interestingly, it could be readily acknowledged that the visual images of the landmarks include places which are of importance such as: main roads, churches, gasoline stations, shopping malls, hospitals, schools, hotels, and ports. In similar vein, Brett \& Schmitz (2009) pointed out that a number of homebuyers and renters who want to walk, bike or take short drive to shopping, recreation, schools and entertainment facilities are increasing. They also mentioned that nearby amenities as well as access to public transportation could be very important to potential residents. Hence, the landmarks involving the commercial centers, churches, schools etc. could be contributing factors in selecting condominiums buys want to own.

Moreover, the location and distance in kilometers are expected to be found in the flyers, rather than focusing on the description of location in minutes. This result conforms to the regulations set in HLURB 921 that instead of indicating the duration of time in traveling to the site of the project, kilometers should be indicated. Nine out of the 30 flyers have presented the details on location and distance in kilometers on either the front or back covers. However, some flyers did not indicate the exact $\mathrm{km} /$ location and just mentioned that it was accessible (F1L18). Some did not express the location in "km." while some locations are just mere phrases but not complete. This suggests that other advertisers shall raise their level of awareness in giving directions to the clients and need to follow the implementing rules and regulations set by HLURB. Putting minutes in the flyers could be misleading to the readers and prospective buyers because of the aggravating traffic and congestion in Cebu City and its neighboring cities and municipalities. In addition, mentioning the duration of time instead of meters or kilometers could be attributed to the Filipino attitude since Filipinos tend to tell events (Interview, Galeon, 2017).

In regard to the website of the developer, most of the prospective buyers will also consider if the developers have websites for them to verify the validity and credibility of the project. The website of the developer yielded the third topmost newly-discovered content of the thirty flyers. Most of the results showcased that this feature was found on the back cover of the flyers and situated on the bottom right portion. Furthermore, there were those flyers like F1, F4, F5, F11 and F13 which websites were found on the front cover plus these were set after the name of the developer. Given that clients nowadays are research-oriented and wise. They therefore intend to study the project viewed online $\&$ in print advertising through the flyers before they decide to invest their money on the chosen condominium project.

Cliff (2012) pointed out that "the site also allows prospective buyers to register and receive updates each time around a listing fitting their profile comes into the market...." (p. 131). This contention was supported by Greenberg \& Kates (2014) that a well-designed website with expert content allows the clients to find the developer/owner whenever they are trying to satisfy a need any time of the day. The occurrence of this newly discovered content of the flyer could be further supported by the study of Cheong (2004 in Nugroho (2009), in which she explicated that there are two components in analyzing print ads: the Visual Images and the Linguistic. In detail, the website of the developer 
found in the flyers belonged to the Linguistic component which gives weight on the Call-and Visit Information. Because a flyer is a promotional medium, the Call-and-Visit Information is vital to be included in the ad for the readers to contact the company if they are interested in the products as well as services. Consequently, the landmark, distance stated in kilometers and websites of the developers could be very important contents of the print advertising which could somehow be included in the mandatory contents.

\section{Conclusions}

The outcomes of the present study express how majority of the flyers of the condominium projects in Cebu are wellthought of. The mandatory contents of the print ads did include the (a) names of the owners and/or developers of the project; (b) exact location of the project including street name, barangay, and city or municipality; (c) the license to sell or amended license to sell number; (d) the advertisement approval number; (e) the approved project completion date as indicted in the license to sell; (f) the maximum selling price in case of economic and socialized housing projects. It could be perceived that the details are composed in a way that suggests a solid grasp of what is imperative to potential viewers as well as buyers. Also, it is apparent that the flyers showcase an interplay of both visual and linguistic sources such as the presence of photos and texts.

Interestingly, there is the presence of varied promotions of the condominiums. First, visual images that focused on water are obvious in the flyers. Five out of the 30 flyers showcased the front cover with a gigantic swimming pool or a body of water to bring more enticement to potential buyers. Second, adjective statements such as "bigger savings, enriching amenities or life just got better" were visible on the front cover. Lastly, one keen presentation of the ads is anchored on the relevance of family. Most flyers included visual images of family members together: be it with a father, mother and children or of a mother with her child. This conclusion, is well-supported by the research of Simpson (2001) which gives worth on advertisements that are anchored on different traditions which reveal great interest on linguistics and discoursal characteristics of advertising. Altogether, the presentation of the contents of the flyers allows the viewers to understand that there is a need to consider as well as understand that the use of text brings about several meanings and that a flyer needs to have a positive image to appeal to the viewers.

\section{Recommendations}

Based on the conclusions, these are the recommendations: The HLURB should be aware that not all flyers contain the license to sell. Thus, the flyers, brochures and other forms of print advertising should be checked before final printing and monitored after the printing. HLURB could gather all graphic artists of developers for the forum concerning the mandatory contents of print forms for marketing to guide them in the inclusion of important parts of the flyer and other sales materials. This study can be a contribution to the upcoming revision of HLURB memo circular series 12015 in relation to the print ads. Fourth, the specific description or map of the location in kilometers should be used. There are still other flyers that provide directions in minutes which is now unacceptable. Students and Faculty members in Linguistics \& Communication can use this study in their classes in discourse analysis and pragmatics as supplementary reading material on textual analysis, advertising and marketing, respectively. The websites, contact numbers of the developers including the various social media icons can also be added to the mandatory contents of the flyers and other print ads. Lastly, studies on critical analysis, collocation of nouns and adjectives, visual images, and deictic expressions in print advertising of real estate could be explored.

\section{References}

[1] Barabas, C. (2017). Genre analysis of Philippine university brochures. Unpublished master's thesis in the University of San Carlos, Cebu City.

[2] "Board Resolution No. 921 Series of 2014: Revised implementing rules and regulations to govern the advertisements of subdivision and condominium projects under Presidential Decree No. 957, Otherwise known as the "Subdivision and Condominium Buyers' Protective Decree" and all other projects required by law to be registered with the housing and land use regulatory board. Retrieved on February 3, $06 \mathrm{t}$ the World Wide Web at http://www.hlurb.gov.ph/lwsissuances/mandates/.pdf.

[3] Brett, D. \& Schnitz, A. (2009). Real estate market analysis: Methods and case studies. 2d. ed. Washington, D.C.: Urban Land Institute.

[4] Cheong W. (2015). Critical discourse analysis of Chinesehousehold appliance advertisements from 1981 to 1996. Unpublished dissertation at the University of NorthamptonChina.

[5] Cliff, P. (2012). The art of selling real estate. Creative Commons Attribution.

[6] Dayag, D. (2008). The Discourse of Print Advertising in the Philippines: Generic Structures and Linguistics Features. Retrieved on March 26, 2017 from https://ai2-s2pdfs.s3.amazonaws.com/e410/9599a7fef4abdda94f46f9ba9fc2 f09492db.pdf.

[7] De Ramos, J. T. (2012). Critical discourse analysis of selected online intercultural news stories in the Philippines: Linguistic and discursive strategies in constructing writers' social identities. Unpublished Dissertation at De La Salle UniversityManila.

[8] "Executive Order No. 71: Devolving the powers of the housing and land use regulatory board to approve subdivision plans, to cities and municipalities pursuant to R No. 7160 , Otherwise known as the Local Government Code of 1991". Retrieved on February 2, 2016 at the World Wide Web at http://www.hlurb.gov.ph/lws-issunces/mndtes/eo_71.pdf.

[9] Greenberg, E. \& Kates, A. (2014). Strategic digital marketing. New York: McGraw Hill. 
[10] Javillonar, M, K. (2016). Discourse features of Philippine billboards: Reconstructing Filipino values and beliefs. Paper presented during the SIMPI International Conference on Urban Studies at Far Eastern University, Manila on May 4-6, 2016.

[11] Ladd, A. (2010). Developing Effective Marketing Materials: Promotional Posters and Flyer Design Considerations. Retrieved on March 15, 2017 from the World Wide Web at https://ag.tennessee.edu/cpa/Information\%20Sheets/cpa180.pd f.

[12] McKee (2002). Textual Analysis: A Beginner's Guide Retrieved on March 15, 2017 from the World Wide Web at http://www1.cs.columbia.edu/ sbenus/Teaching/APTD/McKe e_Ch1.pdf.
[13] Nugroho, A. (2009). The Generic Structure of Print Advertisement of Elizabeth Arden's INTERVENE: A Multimodal Discourse Analysis. Retrieved on March 26, 2017 from http://puslit2.petra.ac.id/gudangpaper/files/784.pdf.

[14] “Textual Analysis" Retrieved March 10, 2017 from the World Wide Web at

http://mason.gmu.edu/ afinn/html/teaching/courses/f03_com m250/fbk_chapters/09.pdf.

[15] Vahid, H. (2012). The Power behind Images: Advertisement Discourse in Focus. International Journal of Linguistics. Retrieved on March 26, 2017 from http://macrothink.org/journal/index.php/ijl/article/viewFile/26 $58 /$ pdf. 